\title{
HLA-DRB1* allele-associated genetic susceptibility and protection against multiple sclerosis in Brazilian patients
}

\author{
DAMACIO RAMÓN KAIMEN-MACIEL ${ }^{1,2}$, EDNA MARIA VISSOCI REICHE ${ }^{3}$, SUELI DONIZETE BORELLI ${ }^{4}$, \\ HELENA KAMINAMI MORIMOTO ${ }^{3}$, FABIANO CAVALCANTE MELO ${ }^{4}$, JOSIANE LOPES ${ }^{2}$, \\ RAFFAEL FERDINANDO DORIGON ${ }^{2}$, CRISTIANE CAVALET ${ }^{2}$, ELTON MAKINO YAMAGUCHI ${ }^{2}$, \\ THIAGO LEITE SILVEIRA ${ }^{2}$, WALDIR VERÍSSIMO DA SILVA JÚNIOR ${ }^{4}$, ELIZABETH REGINA COMINI-FROTA ${ }^{5}$, \\ DORALINA GUIMARÃES BRUM SOUZA ${ }^{5}$ and EDUARDO ANTONIO DONADI ${ }^{6}$

\begin{abstract}
${ }^{1}$ Department of Clinical Medicine, Health Sciences Center, ${ }^{2}$ Outpatient Clinic for Multiple Sclerosis, ${ }^{3}$ Department of Pathology, Clinical Analysis and Toxicology, Health Sciences Center, University Hospital, State University of Londrina, Londrina, Paraná; ${ }^{4}$ Department of Clinical Analysis, Laboratory of Immunogenetics, State University of Maringá, Maringá, Paraná; ${ }^{5}$ School of Medicine, Federal University of Minas Gerais, Belo Horizonte,

Minas Gerais; ${ }^{6}$ School of Medicine of Ribeirão Preto, University of São Paulo, Ribeirão Preto, São Paulo, Brazil
\end{abstract}

Received March 6, 2009; Accepted June 4, 2009

DOI: 10.3892/mmr_00000204

\begin{abstract}
Multiple sclerosis (MS) is a chronic autoimmune demyelinating disease of the central nervous system that causes neurological disorders in young adults. Previous studies in various populations highlighted an association between the HLA-DRB1*15 allele and MS. This study investigated the association between HLA-DRB1"15 and other HLA-DRB1 alleles and MS in a Brazilian Caucasian population sample from Londrina, Southern Brazil. HLA-DRB1 alleles were analyzed by polymerase chain reaction with specific sequence oligonucleotide primers in 119 MS patients and in 305 healthy blood donors as a control. Among the MS patients, $89(75.0 \%)$ presented with relapsing remitting MS, 24 (20.0\%) with secondary progressive MS and $6(5.0 \%)$ with primary progressive MS. The frequency of the HLA-DRB1*15 allele observed in the MS Brazilian patients was similar to findings reported in previous studies carried out in populations worldwide. However, the results showed a higher frequency of the HLA-DRB1* 15 allele in the MS patients compared to the controls, with a relative frequency of $0.1050(10.50 \%)$ and $0.0443(4.4 \%)$, respectively $(\mathrm{OR}=2.53$; $95 \%$ CI $1.43-4.46$; $\mathrm{p}=0.0009$ ). A protector allele was also detected. The frequency of the HLA-DRB 1*11 allele was reduced in the MS patients compared to the controls, with a relative frequency of 0.1345
\end{abstract}

Correspondence to: Dr Edna Maria Vissoci Reiche, Department of Pathology, Clinical Analysis and Toxicology, Health Sciences Center, University Hospital, State University of Londrina, Ave. Robert Koch 60, Vila Operária, CEP 83038-440, Londrina, Paraná, Brazil

E-mail: reiche@sercomtel.com.br

Key words: multiple sclerosis, HLA, HLA-DRB1*, Brazilian population
(13.4\%) and $0.1869(18.7 \%)$, respectively (OR=0.67; $95 \%$ CI 0.44-1.03; $\mathrm{p}=0.0692$ ). The results demonstrated that the HLA-DRB $1 * 15$ allele in heterozygosity is positively associated with MS ( $\mathrm{p}=0.0079)$, and may be considered a genetic marker of susceptibility to the disease. A negative association between the HLA-DRB1"11 allele in homozygosity and MS was also verified $(\mathrm{p}=0.0418)$; this allele may be considered a genetic marker of resistance to MS in the Brazilian population.

\section{Introduction}

Multiple sclerosis (MS) is a chronic inflammatory disease that affects the central nervous system and causes progressive and relapsing neurological disability. It is a complex disease involving several pathological processes, including inflammation, demyelination, axonal damage and repair mechanisms, and an autoimmune response against myelin proteins such as myelin-associated glycoprotein and myelin oligodendrocyte protein mediated by $\mathrm{CD} 4{ }^{+} \mathrm{Th} 1$ lymphocytes and macrophage inflammation into white matter (1). Generally, the onset of MS occurs between 20 and 40 years of age, although it may occur, albeit with low frequency, in children and older adults. Women are affected approximately twice as often as men (2). Criteria for MS diagnosis are currently applied to adult individuals $(3,4)$. Objective criteria include patient clinical history and detailed neurological evaluation, which reveal disease dissemination in time and space. If no clinical symptoms are observed, data from a magnetic resonance image (MRI) of the brain and spinal cord are used as the required evidence of the disease. Other supporting evidence includes cerebrospinal fluid analysis and the results of visual evoked potentials testing. According to the frequency and severity of neurological symptoms, MS is classified as primary progressive (PP-MS), relapsing remitting (RR-MS) or secondary progressive (SP-MS) $(5,6)$ (Lublin FD, American Academy of Neurology 54th Annual Meeting, 2FC.004:13-1, 2002). 
The etiology of MS remains unclear. According to current data, the disease develops in genetically susceptible individuals due to the complex interaction of a number of genes. Each of these contribute a modest effect; however, MS development may require additional triggers, such as hormonal variables and environmental factors including infectious agents and emotional stress. Among the potential genetic host factors, the association between class I and II human leukocyte antigen (HLA) alleles in the 6p21 chromosome and MS has been extensively investigated (2,7-12), and MS familial aggregation has confirmed that the disease has a significant genetic component (13).

Associations with HLA class I molecules $(14,15)$ and, later, with HLA class II molecules (16) have been observed. An association with the haplotypes HLA-A3, B7 and Dw2 was observed in Northern Europeans and in a Caucasian population in the US, but has not been established as universal (17). Furthermore, MHC class II alleles were extensively studied in relation to MS disease behavior $(2,18)$. Susceptibility to MS was first associated with the HLA-Dw2 and -DR2 alleles in Caucasian Europeans and North Americans. With the use of genotyping techniques, a positive association between MS and the HLA-DRB1*1501, -DRB5*0101, -DQA1*0102 and -DQB1*0602 genotypes was demonstrated in Europeans (19-21). A negative association with HLA-DR1, HLA-DQ5 and HLA-DRB1*01 was found in populations from Northern and Western Europe, the Canary Islands and Italy (22-26). A relationship with HLA-DRw6 and its subtype -DRw13 was established among individuals in Mexico (Latin America) (27). It was demonstrated that the combination of -DRB1*1501DQA1*0102-DQB1*0602 (DR15) in northern Europeans and -DRB1*0301-DQA1*0501-DQB1*0301 (DR3) in southern Europeans increases the risk of MS by 3 - to 4-fold $(18,28)$.

Research with Afro-Brazilian patients revealed an association between MS and the HLA-DQB1*0602 allele. This corroborates the results of studies showing an association between HLA-DQB1*0602 and MS, even in the absence of the -DRB1*1501 allele (29). However, further research in Brazil demonstrated that the immune response is not solely affected by the expression of the HLA-DQB1*0602 allele, since no significant statistical difference between the frequency of this allele in MS patients and controls was observed (30). Additional research has shown that the HLA-DRB1*1501 genotype is associated with MS in Caucasian populations (31). Furthermore, the HLA-DRB1*1501 and -DRB1*1503 genotypes have been associated with MS in Caucasian and Mullato individuals (32). A positive association between MS and the HLA-DQB1*0602 and -DQA1*0102 class II alleles has also been demonstrated, and the low frequency of the -DPA $1{ }^{*} 0301$ allele in MS patients suggests that this allele plays a protective role against the disease (Santos CCC, Arq Neuropsiquiatr 60: abs. 1051, 2002).

The Brazilian population is one of the most genetically heterogeneous in the world, consisting of Amerindians, Europeans and Africans (33,34). This extensive ethnic miscegenation suggests that other alleles may be involved in the autoimmune $\mathrm{CD}^{+} \mathrm{T}$ lymphocyte response and in the pathogenesis of MS, affecting either susceptibility or resistance.

Brazilian epidemiological data has shown that the prevalence of MS is highly variable. MS is more frequent in the southern and southeastern regions of Brazil (35). In the city of Londrina, which is located in the north of the state of Paraná in Southern Brazil, the prevalence of MS is 14 per 100,000 inhabitants [Kaimen-Maciel DR, et al, Mult Scler 10 (Suppl 2): abs. 158, 2004].

Data regarding the association between MS and HLA alleles are not consistent among different study populations worldwide, and little data exist concerning the frequency of genetic polymorphisms and their association with protection or susceptibility to MS in the Brazilian population. Therefore, the current study evaluated the frequency of genetic polymorphisms of HLA-DRB1 class II genes and their association with susceptibility to or protection against MS in a Caucasian population in Londrina.

\section{Materials and methods}

The study protocol was approved by the Institutional Research Ethics Committee of the State University of Londrina. Subjects were invited to participate and were informed in detail about the research. Voluntary written consent was obtained from all the individuals included in the study.

Study subjects. The sample population consisted of 119 consecutive non-selected patients diagnosed $(3,4)$ with MS at the Outpatient Clinic for Multiple Sclerosis, University Hospital, State University of Londrina, Londrina, Paraná, Southern Brazil. Of the patients, 89 (75.0\%) presented with RR-MS, $24(20.0 \%)$ with SP-MS and $6(5.0 \%)$ with PP-MS. The control group consisted of 305 age- and sex-matched healthy blood donors. Through medical evaluation, it was ensured that these control individuals were free of acute or chronic internal and neurological diseases. MS patients and controls were of the same ethnicity (Caucasian) and regional location (northern region of the state of Paraná, Southern Brazil).

Genomic DNA extraction. Samples comprising $10 \mathrm{ml}$ of peripheral blood were collected in a vacuum with anticoagulant EDTA and centrifuged at 2,500 rpm for $15 \mathrm{~min}$ to produce a buffy coat. Genomic DNA was extracted from cells in the buffy coat by EZ-DNA Reagent (Biological Industries, Kibbutz Beit Haemek, Israel) following the manufacturer's instructions.

HLA genotyping. The HLA-DRB $1^{*}$ genetic polymorphism was determined by DNA amplification with polymerase chain reaction and hybridized by specific sequence oligonucleotide primers (PCR-SSO) using Luminex technology for HLA genotyping (One Lambda, Canoga Park, CA, USA). Briefly, the reaction consisted of HLA locus-specific amplification with further hybridization by specific probes in the fluorescent microsphere surface. Reading and interpretation of the results were undertaken using a flow cytometer (One Lambda) according to the manufacturer's instructions. Typifying resolution ranged from low to intermediate. The results were also expressed in terms of phenotypic frequency $(F f)$, genotype frequency $(F g)$ determined according to the formula $F g=\sqrt{1-F f}$, and relative frequency $(F r)$, calculated according to the ratio between the number of times the allele appeared in the sample and the total number of alleles evaluated. 
Statistical analysis. A database of the HLA-DRB1* allele results was set up using the Excell program, and allelic frequency was obtained using Statistica 7.0. The Arlequin program v. 2000 (http://anthropologie.unige.ch/arlequin/) (36) was used to verify the association between HLA genotypes and Hardy-Weinberg equilibrium, assessed by calculating the odds ratio (OR) with a confidence interval (CI) of $95 \%$. The level of significance was measured by Fisher's test or the $\chi^{2}$ test $(\mathrm{p} \leq 0.05)$ using Statistica 7.0. The p-value was calculated using the z-test for the comparison of two proportions of two independent samples.

\section{Results}

Profile of the studied subjects. A total of $119 \mathrm{MS}$ patients were enrolled in the study, $84(70.6 \%)$ of them female (female:male ratio 2.4). Of the 305 control individuals, 186 (61.0\%) were female (female:male ratio 1.56). The male:female ratios of the patient and control groups did not differ significantly $\left(\chi^{2}=3.4128, \mathrm{p}=0.0647\right)$. The chronological ages of the MS patients ranged from 18 to 79 years (mean 44.2 \pm 11.9 years) with a median of 435 years and an interquartile range (IQR) of 35-53 years. Among the controls, the ages ranged from 18 to 54 years (mean $33.3 \pm 9.5$ years) with a median of 33 years and an IQR of 25-40 years. The mean ages of the two groups differed significantly (Student's t-test, $\mathrm{p}<0.0001$ ) (Table I).

The age at MS onset ranged from 10 to 68 years (mean $36.3 \pm 12.1$ years) with a median of 36 years and an IQR of 27-45 years; i.e., $75 \%$ of patients exhibited the initial symptoms of MS before the age of 45 years.

HLA-DRB1 allele frequency. The frequency of the HLA-DRB1* alleles observed in the MS patients and controls was in HardyWeinberg equilibrium. Table II shows the allelic frequency in
Table I. Demographic characteristics of multiple sclerosis patients and healthy controls from Londrina, Southern Brazil.

\begin{tabular}{lccc}
\hline & $\begin{array}{c}\text { MS patients } \\
(\mathrm{n}=119)\end{array}$ & $\begin{array}{c}\text { Healthy controls }^{\mathrm{b}} \\
(\mathrm{n}=305)\end{array}$ & P-value \\
& & & $0.0647^{\mathrm{c}}$ \\
Gender & $84(70.6)$ & $186(61.0)$ & \\
Female, no. (\%) & $35(29.4)$ & $119(39.0)$ & \\
Male, no. (\%) & 2.4 & 1.56 & \\
Female:male ratio & & & $<0.0001^{\mathrm{d}}$ \\
Age (years) & & & \\
Range & $18-79$ & $18-54$ & \\
Mean \pm SD & $44.2 \pm 11.2$ & $33.3 \pm 9.5$ & \\
Median (IQR) & $45(35-53)$ & $33(25-40)$ & \\
\hline
\end{tabular}

aEighty-nine (75.0\%) patients presented with relapsing remitting multiple sclerosis (MS), 24 (20.0\%) with secondary progressive MS and 6 (5.0\%) with primary progressive MS. ${ }^{\text {b }}$ Control individuals were healthy blood donors. ' $\chi^{2}$ test; 'Student's t-test; SD, standard deviation; IQR, interquartile range.

MS patients and controls. Among the 119 MS patients, a total of 238 alleles were evaluated and distributed into 13 distinct types. The HLA-DRB1* $11 /{ }^{*} \mathrm{X}$ allele was detected 32 times, whereas the-DRB1 ${ }^{*} 9 /{ }^{*} \mathrm{X}$ allele was not detected in MS patients. Among the 305 controls, a total of 610 alleles were evaluated and distributed into 13 distinct types. The HLA-DRB1* $11 /{ }^{*} \mathrm{X}$ allele was detected 114 times and the $-\mathrm{DRB1}{ }^{*} 9 /{ }^{*} \mathrm{X}$ allele eight times in the controls. Table II also shows the $F f, F g$ and $F r$ of the alleles evaluated.

Table II. Distribution of the frequency, phenotypic frequency, genotypic frequency and relative frequency of class II HLA-DRB1* alleles in 119 multiple sclerosis patients and 305 healthy blood donors from Londrina, Southern Brazil.

\begin{tabular}{|c|c|c|c|c|c|c|c|c|}
\hline \multirow[b]{2}{*}{ HLA-DRB1* allele } & \multicolumn{4}{|c|}{ MS patients $(n=119)$} & \multicolumn{4}{|c|}{ Healthy blood donors $(n=305)$} \\
\hline & Frequency (no.) & $F f^{\mathrm{a}}$ & $F^{b}$ & $F r^{c}$ & Frequency (no.) & $F f^{\mathrm{a}}$ & $F g^{\mathrm{b}}$ & $F r^{c}$ \\
\hline 01 & 26 & 0.2185 & 0.1160 & 0.1092 & 72 & 0.2361 & 0.1260 & 0.1180 \\
\hline 03 & 31 & 0.2605 & 0.1401 & 0.1303 & 63 & 0.2066 & 0.1092 & 0.1033 \\
\hline 04 & 27 & 0.2269 & 0.1207 & 0.1134 & 74 & 0.2426 & 0.1297 & 0.1213 \\
\hline 07 & 28 & 0.2353 & 0.1255 & 0.1176 & 79 & 0.2590 & 0.1392 & 0.1295 \\
\hline 08 & 20 & 0.1681 & 0.0879 & 0.0840 & 41 & 0.1344 & 0.0696 & 0.0672 \\
\hline 09 & 0 & 0.0000 & 0.0000 & 0.0000 & 8 & 0.0262 & 0.0132 & 0.0131 \\
\hline 10 & 5 & 0.0420 & 0.0212 & 0.0210 & 11 & 0.0361 & 0.0182 & 0.0180 \\
\hline 11 & 32 & 0.2689 & 0.1450 & 0.1345 & 114 & 0.3738 & 0.2087 & 0.1869 \\
\hline 12 & 2 & 0.0168 & 0.0084 & 0.0084 & 9 & 0.0295 & 0.0149 & 0.0148 \\
\hline 13 & 25 & 0.2101 & 0.1112 & 0.1050 & 71 & 0.2328 & 0.1241 & 0.1164 \\
\hline 14 & 11 & 0.0924 & 0.0473 & 0.0462 & 19 & 0.0623 & 0.0316 & 0.0311 \\
\hline 15 & 25 & 0.2101 & 0.1112 & 0.1050 & 27 & 0.0885 & 0.0453 & 0.0443 \\
\hline 16 & 6 & 0.0504 & 0.0255 & 0.0252 & 22 & 0.0721 & 0.0367 & 0.0361 \\
\hline
\end{tabular}

${ }^{\mathrm{a}} \mathrm{Ff}$, phenotypic frequency; calculated by the ratio between the number of times that the allele appears in the sample and the total number of patients under analysis. ${ }^{\mathrm{b}} \mathrm{Fg}$, genotypic frequency; expressed as $F g=\sqrt{1-F f} .{ }^{\mathrm{c}} \mathrm{Fr}$, relative frequency; calculated by the ratio between the number of times the allele appeared in the sample and the total number of alleles distributed. MS, multiple sclerosis. 
Table III. Odds ratio and $95 \%$ confidence interval according to the presence or absence of the HLA-DRB1* class II alleles detected in 119 multiple sclerosis patients and 305 healthy controls from Londrina, Southern Brazil.

\begin{tabular}{|c|c|c|c|c|c|}
\hline \multirow[b]{2}{*}{ HLA-DRB1* allele } & \multicolumn{2}{|c|}{ Frequency (no.) } & \multirow[b]{2}{*}{ OR } & \multirow[b]{2}{*}{$95 \% \mathrm{CI}$} & \multirow[b]{2}{*}{ P-value } \\
\hline & $\begin{array}{l}\text { MS patients } \\
\quad(n=119)\end{array}$ & $\begin{array}{l}\text { Healthy controls } \\
\qquad(n=305)\end{array}$ & & & \\
\hline 01 & 26 & 72 & 0.9164 & $0.5695-1.4747$ & 0.7191 \\
\hline 03 & 31 & 63 & 1.3003 & $0.8218-2.0572$ & 0.2609 \\
\hline 04 & 27 & 74 & 0.9269 & 0.5801-1.4809 & 0.7507 \\
\hline 07 & 28 & 79 & 0.8962 & $0.5659-1.4193$ & 0.6402 \\
\hline 08 & 20 & 41 & 1.2732 & $0.7295-2.2221$ & 0.3943 \\
\hline 09 & 0 & 8 & - & - & - \\
\hline 10 & 5 & 11 & 1.1686 & $0.4017-3.3997$ & 0.7746 \\
\hline 11 & 32 & 114 & 0.6759 & $0.4421-1.0332$ & 0.0692 \\
\hline 12 & 2 & 9 & 0.5659 & $0.1214-2.6386$ & 0.4627 \\
\hline 13 & 25 & 71 & 0.8910 & $0.5499-1.4438$ & 0.6394 \\
\hline 14 & 11 & 19 & 1.5073 & $0.7062-3.2172$ & 0.2857 \\
\hline 15 & 25 & 27 & 2.5343 & $1.4387-4.4643$ & 0.0009 \\
\hline 16 & 6 & 22 & 0.6912 & $0.2767-1.7265$ & 0.4267 \\
\hline
\end{tabular}

${ }^{a} \chi^{2}$ test for homogeneity. OR, odds ratio; CI, confidence interval, MS muliple sclerosis.

Table IV. Frequency of the homozygosity and heterozygosity of the HLA-DRB1* class II alleles evaluated in 119 multiple sclerosis patients and 305 healthy controls from Londrina, Southern Brazil.

\begin{tabular}{lccc}
\hline & \multicolumn{2}{c}{ Frequency (no.) } & \\
\cline { 2 - 3 } HLA-DRB1 $^{*}$ allele & $\begin{array}{c}\text { MS patients } \\
(\mathrm{n}=119)\end{array}$ & $\begin{array}{c}\text { Healthy controls } \\
(\mathrm{n}=305)\end{array}$ & \\
\hline Homozylue & \\
11,11 & & & \\
15,15 & 1 & 16 & 0.0418 \\
X, X & 2 & 1 & 0.1367 \\
Heterozygosity & 14 & 37 & 0.9222 \\
$11, \mathrm{X}$ & & & \\
$15, \mathrm{X}$ & 30 & 82 & 0.7630 \\
$\mathrm{X}, \mathrm{Y}$ & 21 & 25 & 0.0079 \\
\hline
\end{tabular}

${ }^{a}$ Z-test for the comparison of two proportions of two independent samples. ${ }^{b}$ HLA-DRB1* class II alleles different from alleles 11 and 15.

Table III shows the OR and 95\% CI according to the presence or absence of class II HLA-DRB1* alleles detected in the MS patients and controls. Out of 13 alleles, only the HLADRB1 $15 /{ }^{*} \mathrm{X}$ allele, in which $\mathrm{X}$ represents a heterozygous allele, had a significant OR. When the -DRB1* $15 /{ }^{*} \mathrm{X}$ allele was taken into account, the OR was 2.5343 (95\% CI 1.4387-4.4643). This indicates that for each HLA-DRB1 ${ }^{*} 15 /{ }^{*} \mathrm{X}$ allele detected in the controls, 2.5343 HLA-DRB1 ${ }^{*} 15{ }^{*} \mathrm{X}$ alleles were detected in the MS patients, resulting in a significant difference between the two groups ( $\chi^{2}$ test for homogeneity, $\mathrm{p}=0.0009$ ). An OR of 0.6759 (95\% CI 0.4421-1.0332) was also found for the HLADRB1 ${ }^{*} 11 /{ }^{*} \mathrm{X}$ allele, where $\mathrm{X}$ represents a heterozygous allele ( $\chi^{2}$ test for homogeneity, $\mathrm{p}=0.0692$ ). Although this result did not differ significantly between the two groups, it suggests that the $-\mathrm{DRB} 1{ }^{*} 11 /{ }^{*} \mathrm{X}$ allele may contribute towards resistance to MS development, since for each -DRB1*11/*X allele detected in the controls, 0.6759 -DRB1* $11{ }^{*} \mathrm{X}$ alleles were detected in the MS patient group.

Table IV shows the results of HLA-DRB1* genotyping with alleles in homozygosity and heterozygosity in the MS patients and controls. The frequency of homozygous -DRB1* $11 /^{*} 11$ in MS patients and controls was significantly different (z-test, $\mathrm{p}=0.0418$ ), indicating that this homozygosity may contribute to resistance to MS development. However, there was no significant difference ( $\mathrm{z}$-test, $\mathrm{p}=0.1367$ ) between the frequency of homozygous -DRB1* $15{ }^{*} 15$ in the MS patients and controls. Additionally, no significant difference (z-test, $\mathrm{p}=0.9172$ ) was found between the frequencies observed in the two groups when all homozygous -DRB1* $\mathrm{X} /{ }^{*} \mathrm{X}$ alleles were taken into account. The frequency of the heterozygous -DRB1* $15{ }^{*} \mathrm{X}$ allele in MS patients and controls was significantly different (z-test, $\mathrm{p}=0.0079$ ), suggesting that heterozygosity of the HLA-DRB1* alleles may contribute to susceptibility to MS. Nevertheless, the frequency of heterozygous -DRB1*11/*X in the MS patients and controls was not significantly different (z-test, $\mathrm{p}=0.7630$ ). Moreover, no significant difference (z-test, $\mathrm{p}=0.9712$ ) was found between the frequencies observed in the two groups when all heterozygous -DRB1 $\mathrm{X} /{ }^{*} \mathrm{Y}$ alleles were taken into account.

Table V shows the results of HLA-DRB1* genotyping for allele pairs in heterozygosity according to the presence of the 
Table V. Frequency of the HLA-DRB1* class II allele genotype for heterozygous pairs with regard to the presence of -DRB1* $15 / * \mathrm{X}$ evaluated in 119 multiple sclerosis patients and 305 healthy controls from Londrina, Southern Brazil.

\begin{tabular}{lccc}
\hline $\begin{array}{l}\text { Heterozygous } \\
\text { pairs of }\end{array}$ & \multicolumn{3}{c}{ Frequency (no.) } \\
\cline { 2 - 3 } $\begin{array}{l}\text { HLA-DRB1* } \\
\text { alleles }\end{array}$ & $\begin{array}{c}\text { MS patients } \\
(\mathrm{n}=119)\end{array}$ & $\begin{array}{c}\text { Healthy controls } \\
(\mathrm{n}=305)\end{array}$ & P-value \\
\hline 15,01 & 1 & 6 & 0.4147 \\
15,03 & 4 & 0 & 0.0014 \\
15,04 & 1 & 3 & 0.8886 \\
15,07 & 4 & 4 & 0.1694 \\
15,08 & 2 & 2 & 0.3320 \\
15,10 & 1 & 1 & 0.4921 \\
15,11 & 3 & 2 & 0.1133 \\
15,13 & 2 & 7 & 0.6925 \\
15,14 & 2 & 0 & 0.0239 \\
15,16 & 1 & 0 & 0.1101 \\
\hline
\end{tabular}

${ }^{\mathrm{a}}$ z-test for the comparison of two proportions of two independent samples. MS, multiple sclerosis.

-DRB1* $15 / * \mathrm{X}$ allele. There was a significant difference in terms of the frequency of the heterozygote pairs (105 for MS patients and 268 for controls) in -DRB1 ${ }^{*} 15 /{ }^{*} 03$ and -DRB1* $15 /^{*} 14$ allele pairs ( $\mathrm{p}=0.0014$ and $\mathrm{p}=0.0239$, respectively). This result suggests that the presence of HLA-DRB1*15/X in heterozygosity may contribute to susceptibility to MS development.

\section{Discussion}

The major histocompatibility complex (MHC) is a 6p21 chromosome region comprising a set of genes that encodes cell surface alloantigens. The HLA system is a subset of the human MHC, divided into class I and class II HLA genes (37).

Several genetic and epidemiological studies have verified the contribution of genetic factors to MS development. Although MS is associated with polygenic involvement, there is a well established association between the HLA system alone and MS (10,11). MS also affects more females than males; though the mechanisms behind this difference remain unclear, hormonal variables are likely to act as risk factors. This hypothesis is supported by lower relapse rates during pregnancy and disease rebound following birth, and a worsening of MS during the menstruation period (2). Studies suggest that steroid hormones affect the development and severity of MS $(38,39)$. In accordance with previous reports, the current study confirmed a higher frequency of MS-affected female patients than males. The age at disease onset in the MS patients evaluated in this study was equal to or younger than 27 years in $25 \%$ and equal to or younger than 45 years in $75 \%$ of the patients. These results are also in agreement with previous reports $(2,40,41)$.

The frequency of the -DRB1*15 allele detected in the present study showed that this allele is potentially a significant factor for MS susceptibility and development $(\mathrm{OR}=2.5343$;
95\% CI 1.4387-4.4643; $\mathrm{p}=0.009$ ). This result corroborates studies that found an association between -DRB1*15 and MS in a Brazilian Caucasian population $(31,32)$.

Several studies have revealed that, in certain populations, the -DR1, -DR7 and -DR11 MHC class II molecules act as resistance molecules in MS development $(42,43)$. In the present study, the -DRB1*11 allele in MS patients was associated with resistance to MS development, with a trend towards a protective role $(\mathrm{OR}=0.6759 ; 95 \%$ CI $0.4421-1.0332 ; \mathrm{p}=0.0692)$. Further studies comprising a larger number of individuals carrying the -DRB ${ }^{*} 11$ allele are needed to confirm its role in protection against MS.

Homozygous and heterozygous frequency analysis between the -DRB1*15 and -DRB1*11 alleles showed that these genetic factors may be considered susceptibility and protective indicators, respectively, with regards to MS development. The results also showed that, in the case of the protective -DRB1*11 allele, homozygosity may confer protection against disease development $(\mathrm{p}=0.0418)$. On the other hand, homozygosity for the -DRB1*15 allele failed to show any association with susceptibility to MS. This may be due to the limited number of patients evaluated in the present study. In a comparative analysis of the heterozygous allelic pairs detected among the controls and MS patients, expressed by -DRB1*15/X (in which X represents other alleles in combination with allele *15), a significant difference was observed in the frequency of the heterozygote pairs -DRB1*15/03 ( $\mathrm{p}=0.0014)$ and -DRB1 ${ }^{*} 15 /^{*} 14(\mathrm{p}=0.0239)$. This suggests that increased susceptibility to MS development can be attributed to these heterozygotes.

The results also corroborated a study carried out with 1339 families showing that the -DRB1 ${ }^{*} 15$ allele was strongly associated with MS development $(\mathrm{p}=0.0078)$ and confirming a dominant dose-effect of the -DRB1*15 allele (OR=7.5; 95\% CI 4.4-13.0; p<0.0001). A slight dose-effect was also detected for the -DRB1 ${ }^{*} 03$ allele. In addition, high risk for the -DRB1*15/08 allele was identified (OR=7.7; 95\% CI 4.1-14.4; $\mathrm{p}<0.0001$ ), providing additional evidence for trans-DRB1* allele interactions in MS (44).

The heterozygosity frequencies in the HLA-DRB1* class II alleles observed in the MS patients or in the healthy control individuals evaluated in this study can be explained by the heterogeneous ethnic composition of the Brazilian population. Genetically, populations with greater homogeneity have a higher frequency of alleles in homozygosity $(33,34)$.

The high variability in the natural evolution of MS reinforces the need for a better understanding of the genetically heterogeneous conditions of populations harboring MS individuals. Studies of HLA genetic polymorphisms in a specific population may identify a genotype or an association of genotypes that could be considered a risk factor for disease development and progression. Considering that the MHC genes are the most polymorphic genes presented in the genome of every species analyzed (45), and that a highly complex interaction between multiple cell types and molecules of the immune system is involved in the mechanisms of MS (2), further studies carried out in genetically heterogeneous populations are needed to identify the risk factors and biomarkers of MS.

In addition to the HLA system, several candidate genes have been studied for disease-modifying effects in MS. Polymorphisms of the interleukin 4 , interferon $\alpha$, chemokine 5 
receptor, interleukin 10, IL-4 receptor, interleukin 2 receptor $\beta$, apolipoprotein $\mathrm{E}$ and estrogen receptor genes have been associated with risk in MS; polymorphisms of the chemokine receptor 2, IL-10 receptor, interleukin-1 $\beta$ and IL-1 receptor antagonist genes have been associated with protection against MS $(2,18)$.

Elucidation of the role of host genetic factors may contribute to a more thorough knowledge of MS pathogenesis, and may eventually improve therapeutic approaches to modulating the autoimmune responses involved in MS. The early detection of genetic factors which contribute to the rapid progression of the disease guarantees the use of varied and aggressive therapeutic strategies for MS patients and facilitates the monitoring of clinical symptoms and MRI findings. Considering the continuous and rapid progress in the field of pharmacogenetics, elucidation of the genetic factors involved in resistance and susceptibility to MS may contribute to the development of future therapies for MS that take into account these host genetic factors.

\section{References}

1. Kallmann BA and Rieckmann P: Chemokines and MS lesion development. Int MS J 9: 101-107, 2001.

2. Sospedra M and Martin R: Immunology of multiple sclerosis. Ann Rev Immunol 23: 683-747, 2005.

3. McDonald WI, Compston A, Edan G, et al: Recommended diagnostic criteria for multiple sclerosis: guidelines from the International Panel on the diagnosis of multiple sclerosis. Ann Neurol 50: 121-127, 2001

4. Polman CH, Reingold SC, Edan G, et al: Diagnostic criteria for multiple sclerosis: 2005 revisions to the 'McDonald Criteria'. Ann Neurol 58: 840-846, 2005.

5. Lublin FD and Reingold SC: Defining the clinical course of MS. Neurology 46: 907-911, 1996.

6. Arruda WO, Scola RH, Teive HA, and Werneck LC: Multiple sclerosis: report on 200 cases from Curitiba, Southern Brazil, and comparison with other Brazilian series. Arq Neuropsiquiatr 59: 165-170, 2001.

7. Oksenberg JR, Panzara MA, Begovich $\mathrm{AB}$, et al: Selection for T-cell receptor $\mathrm{V}$ beta-D beta-J beta gene rearrangements with specificity for a myelin basic protein peptide in brain lesions of multiple sclerosis. Nature 362: 68-70, 1993.

8. Sadovnick AD, Ebers GC, Dyment DA and Risch NJ: Evidence for genetic basis of multiple sclerosis. The Canadian Collaborative Study Group. Lancet 347: 1728-1730, 1996.

9. Klein J and Sato A: The HLA system. First of two parts. New Engl J Med 343: 702-709, 2002.

10. Oksenberg JR, Baranzini SE, Barcellos LF and Hauser SL: Multiple sclerosis: genomic rewards. J Neuroimmunol 113: 171-184, 2001

11. Hensiek AE, Sawcer SJ, Feakes R, et al: HLA-DR15 is associated with female sex and younger age at diagnosis in multiple sclerosis. J Neurol Neurosurg Psychiatry 72: 184-187, 2002.

12. Hemminki K, Li X, Sundquist J, Hillert J and Sundquist K: Risk for multiple sclerosis in relatives and spouses of patients diagnosed with autoimmune and related conditions. Neurogenetics 10: 5-11, 2009.

13. Ebers GC: Genetic epidemiology of multiple sclerosis. Curr Opin Neurol 9: 155-158, 1996.

14. Naito S, Namerow N, Mickey M and Terasaki PI: Multiple sclerosis: association with HL-A3. Tissue Antigens 2: 1-4, 1972.

15. Jersild C, Svejgaard A and Fog T: HLA antigens and multiple sclerosis. Lancet 2: 240-241, 1972.

16. Winchester R, Ebers G, Fu SM, Espinosa L, Zabriskie J and Kunkel HG: B-cell alloantigen Ag 7a in multiple sclerosis. Lancet 2: 814, 1975.

17. Brautbar C, Amar A, Cohen I, et al: Histocompatibility (HLA) antigens and multiple sclerosis in Israelis. Isr J Med Sci 18: 631-634, 1982.

18. Kantarci $\mathrm{OH}$, Andrade $\mathrm{M}$ and Weinshenker BG: Identifying disease modifying genes in multiple sclerosis. J Neuroimmunol 123: 144-159, 2002.
19. Olerup O and Hillert J: HLA class II-associated genetic susceptibility in multiple sclerosis: a critical evaluation. Tissue Antigens 38: 1-15, 1991 .

20. Fogdell A, Hillert J, Sachs C and Olerup O: The multiple sclerosisand narcolepsy-associated HLA class II haplotype includes the DRB5*0101 allele. Tissue Antigens 46: 333-336, 1995.

21. Dyment DA, Stecklev JL, Morrison K, et al: TCR beta polymorphisms and multiple sclerosis. Genes Immun 5: 337-342, 2004.

22. Weinshencker BG, Santrach P, Bissonet AS, et al: Major histocompatibility complex class II alleles and the course and outcome of MS: a population-based study. Neurology 51: 742-747, 1998.

23. Siva A, Kesselring J and Thompson A(eds): Frontiers in Multiple Sclerosis. 1st edition. Martin-Dunitz, London, pp51-61, 1999.

24. Hillert J: Human leukocyte antigen studies in multiple sclerosis. Ann Neurol 36: S15-S17, 1994.

25. Ballerini C, Guerini FR, Rombolà G, et al: HLA-multiple sclerosis association in continental Italy and correlation with disease prevalence in Europe. J Neuroimmunol 150: 178-185, 2004.

26. Coraddu F, Reyes-Yanez MP, Parra A, Gray J, Smith SI, Taylor CJ and Compston DAS: HLA associations with multiple sclerosis in the Canary Islands. J Neuroimmunol 87: 130-135, 1998.

27. Gorodezky C, Najera R, Rangel BE, et al: Immunogenetic profile of multiple sclerosis in Mexicans. Hum Immunol 16: 364-374, 1986.

28. Zivadinov R, Uxa L, Zacchi T, et al: HLA genotypes and disease severity assessed by magnetic resonance imaging findings in patients with multiple sclerosis. J Neurol 250: 1099-1106, 2003.

29. Caballero A, Alves-Leon S, Papais-Alvarenga R, Fernandez O, Navarro G and Alonso A: DQB1*0602 confers genetic susceptibility to multiple sclerosis in Afro-Brazilians. Tissue Antigens 54: 524-526, 1999.

30. Carvalho A, Sant'Anna G, Santos CC, Frulhetti IP, Leon AS and Quírico-Santos T: Determination of autoantibody for myelin antigens in the serum of patients HLA-DQB $1{ }^{*} 0602$ with multiple sclerosis. Arq Neuropsiquiatr 61: 968-973, 2003.

31. Alves-Leon SV, Papais-Alvarenga R, Magalhães M, Thuler LCS and Fernández y Fernandez O: Ethnicity-dependent association of HLA DRB1-DQA1-DQB1 alleles in Brazilian multiple sclerosis patients. Acta Neurol Scand 115: 306-311, 2007.

32. Brum DG, Barreira AA, Louzada-Junior P, Mendes-Junior CT and Donadi EA: Association of the HLA-DRB1*15 allele group and the DRB1*1501 and DRB1*1503 alleles with multiple sclerosis in White and Mulatto samples from Brazil. J Neuroimmunol 189: 118-124, 2007.

33. Parra FC, Amado RC, Lambertucci JR, Rocha J, Antunes CM and Pena SD: Color and genomic ancestry in Brazilians. Proc Natl Acad Sci USA 100: 177-182, 2003.

34. Pimenta JR, Zuccherato LW, Debes AA, et al: Color and genomic ancestry in Brazilians: a study with forensic microsatellites. Hum Hered 62: 190-195, 2006.

35. Cardoso E, Fukuda T, Pereira J, et al: Clinical and epidemiological profile of multiple sclerosis in a reference center in the State of Bahia, Brazil. Arq Neuropsiquiatr 64: 727-730, 2006.

36. Schneider S, Roessli D and Excoffier L: Arlequim: a software for population data analysis. University of Geneva, Genetic and Biometry Laboratory, Geneva, 2000.

37. Sachs JA, Kuo MC, Johnson AH, et al: The detection of HLA-DR, $\mathrm{MB}$ and MT determinants on purified class II molecules by inhibition of microcytotoxicity. J Immunol Methods 73: 387-399, 1984.

38. Drew PD and Chavis JA: Sex steroid regulation of microglial cell activation: relevance to multiple sclerosis. Ann NY Acad Sci 1007: 329-334, 2003.

39. Van den Broek HH, Damoiseaux JG, De Baets MH and Hupperts RM: The influence of sex hormones on cytokines in multiple sclerosis and experimental autoimmune encephalomyelitis: a review. Mult Scler 11: 349-359, 2005.

40. Paty DW and Ebers GC (eds): Clinical features. In: Multiple Sclerosis. FA Davis, Philadelphia, pp135-191, 1977.

41. O'Connor P: Key issues in the diagnosis and treatment of multiple sclerosis: an overview. Neurology 59: S1-S33, 2002.

42. Giordano M, D'Alfonso S and Momigliano-Richiardi P: Genetics of multiple sclerosis: linkage and association studies. Am J Pharmacogenomics 2: 37-58, 2002.

43. Dean G, Yeo TW, Goris A, et al: HLA-DRB1 and multiple sclerosis in Malta. Neurology 70: 101-105, 2008.

44. Barcellos LF, Sawcer S, Ramsay PP, et al: Heterogeneity at the HLA-DRB1 locus and risk for multiple sclerosis. Hum Mol Genet 15: 2813-2824, 2006.

45. Abbas AK, Lichtman AH and Pober JS: Cellular and Molecular Immunology. 4th edition, W.B.Saunders Company, Philadelphia, pp63-78, 2000. 